\title{
A Case of Pure Matrix Ureteral Stone A rare type of urinary calculi that may be overlooked
}

"Mohamed M. Elawdy, ${ }^{1}$ Samer El-Halwagy, ${ }^{1}$ Yasser A. Razek, ${ }^{2}$ Abeer R. Alsenani, ${ }^{3}$ Sultan Almazroui ${ }^{3}$

$$
\text { حالة لحصوات الحالب البولى القالبية }
$$

$$
\text { محمد محمد العوضي، سامر الحلوجي، ياسر عبد الرازق، عبير راشد السناني، سلطان المزروعي }
$$

ABSTRACT: Matrix stones are a rare form of urinary calculi with a low mineral content. We report a 63-year-old female patient who presented to the Sohar Hospital, Sohar, Oman, in 2018 with unexplained left flank pain and constipation. She had a history of chronic renal failure (CRF) and had previously undergone haemodialysis (HD). Non-contrast computed tomography (CT) did not show any renal or urinary stones. However, a left-sided ureteroscopy revealed a yellow-coloured stone that was soft in consistency occupying the proximal $5 \mathrm{~cm}$ section of the ureter. Many attempts at forceps extraction were required for complete clearance. A global quantitative composition analysis revealed the extracted stone to be composed entirely of protein-matrix material. Matrix stones require a high index of suspicion as they are sometimes radiolucent and cannot be visualised on CT scans. Risk factors include being female and a history of urinary tract infections, CRF and HD.

Keywords: Urolithiasis; Ureteral Calculi; Diagnostic Imaging; Ureteroscopy; Case Report; Oman.

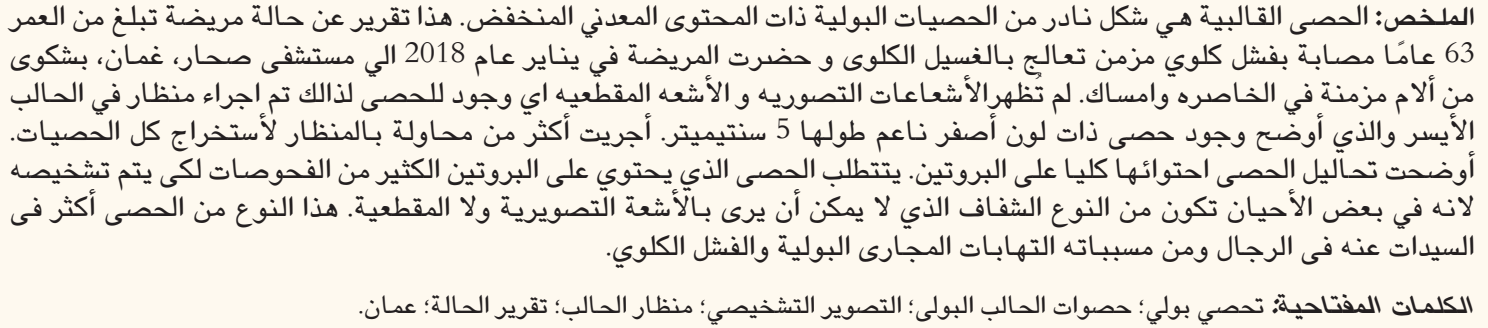

$\mathrm{M}$ ATRIX STONES ARE A RARE FORM OF URINARY calculi, with most reported cases related to renal stones and few cases of ureteral stones. ${ }^{1,2}$ Matrix stones are formed within the renal collecting system and are composed of soft mucoproteinaceous material. ${ }^{3}$ In normal calcareous calculi, protein usually accounts for no more than $2.5 \%$ of the dry weight of the stone; however, in matrix calculi, it accounts for between $42-84 \% .{ }^{4}$

Pure matrix stones consist solely of protein and are therefore completely radiolucent and cannot be visualised, even on computed tomography (CT); as such, there is a risk of such stones being missed. ${ }^{1-3}$ This case report describes a patient with a pure matrix ureteral stone which was initially overlooked, resulting in a delay in diagnosis and management. Such cases may help to increase awareness of this rare form of urinary calculi among urologists and radiologists.

\section{Case Report}

A 63-year-old female patient presented to the emergency department of the Sohar Hospital, Sohar, Oman, in 2018 with left-sided abdominal pain, dyspepsia and constipation.
She had a medical history of ischaemic heart disease as well as chronic renal failure (CRF), for which she had undergone haemodialysis (HD). A physical examination revealed left costovertebral angle tenderness and mild abdominal distension. Routine laboratory investigations revealed a low haemoglobin $(\mathrm{Hb})$ level of $9 \mathrm{~g} / \mathrm{dL}$, likely due to the CRF and HD. A urine analysis revealed elevated levels of red blood cells (RBCs) and white blood cells (WBCs) at $>60$ cells/high power field, indicative of a urinary tract infection (UTI). In addition, a urine culture was positive for Escherichia coli.

Ultrasonography (US) revealed that both kidneys were small, with increased cortical echogenicity and loss of corticomedullary differentiation. A CT scan showed moderate left-sided hydroureteronephrosis down to the level of the pelvic ureter, with no stones visible and perirenal and periureteral fat stranding [Figure 1]. As such, the patient was treated conservatively. However, five days later, she presented to another hospital where she underwent a left-sided ureteroscopy (URS) and the insertion of a Double-J ureteral stent.

Two weeks later, the patient presented once again to Sohar Hospital due to persistent pain. At this time, an 

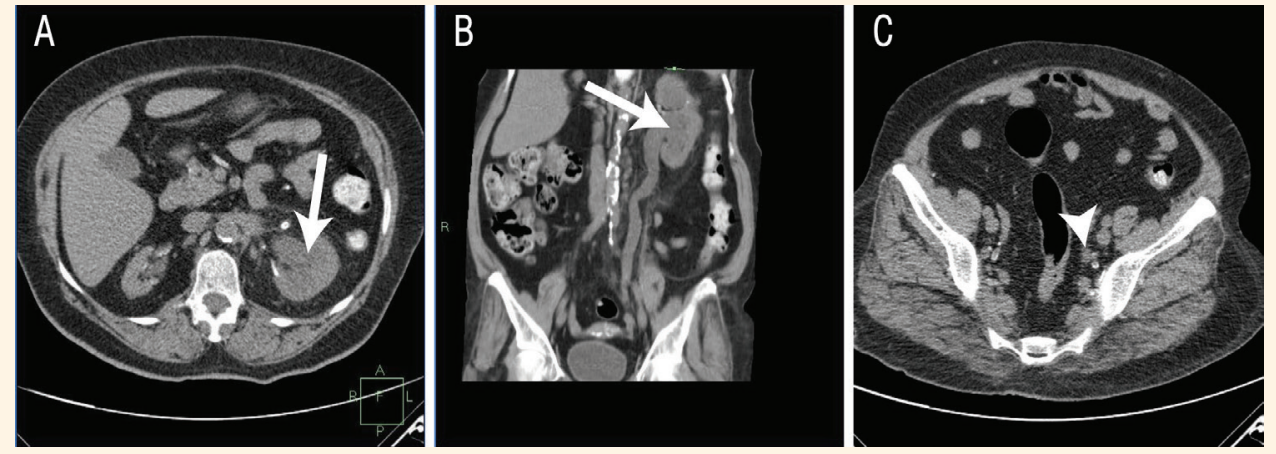

Figure 1: Non-contrast computed tomography scans of the abdomen of a 63-year-old female patient with unexplained left flank pain and constipation showing moderate hydroureteronephrosis (arrows), but no visible stones at the level of the distal obstruction (arrowhead).

abdominal X-ray showed that most of the left Double-J ureteral stent had descended into the urinary bladder. A cystoscopy and left-sided URS was performed, during which the Double-J stent was removed and insertion of a left guidewire was attempted; however, this failed as the wire could not be inserted past the level of the midureter. This was due to the presence of a long yellowcoloured stone located in the proximal $5 \mathrm{~cm}$ section of the ureter. The stone itself was soft, malleable and viscous in consistency. After many trials, the stone was eventually removed by forceps and the ureteroscope could be freely navigated to the kidney.

After extraction, the fragments of the stone appeared black and elongated [Figure 2]. A global quantitative composition analysis revealed the stone to be composed of $100 \%$ protein-matrix material. In terms of management, an open-tip ureteral tube was left in for 48 hours before the patient was discharged. At a two-week follow-up visit, she reported a significant reduction in pain. A urine analysis revealed no abnormalities, except for slight levels of RBCs and WBCs.

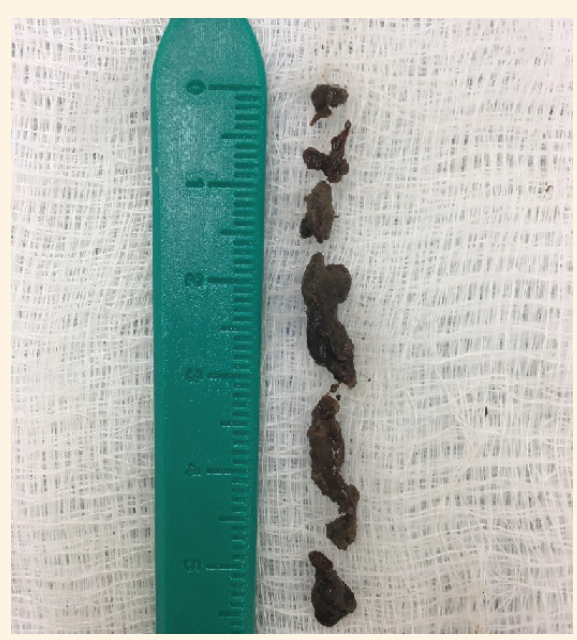

Figure 2: Gross photograph of elongated black fragments of an extracted ureteral matrix stone found to be composed entirely of protein.

\section{Discussion}

Overall, matrix stones are more common in female patients; Rowley et al. reported that seven out of nine patients in a cases series were female. ${ }^{2}$ This may be explained by the higher frequency of UTIs among women, another risk factor for matrix stone formation; in Rowley et al's cases series, all nine patients had UTIs, while Shah et al. reported that $80 \%$ of 17 patients with matrix calculi had pyuria., ${ }^{2,5}$ In the present case, the patient was female and had a UTI, as determined by elevated levels of RBCs and WBCs in her urine and a positive E. coli culture.

Glomerular diseases and CRF may also predispose patients to matrix stone formation due to higher protein content in the urine. ${ }^{6-8}$ Based on chemical analysis and transmission and scanning electron microscopy, Bommer et al. reported that de novo stones in seven patients undergoing $\mathrm{HD}$ were composed of an amorphous organic matrix consisting predominantly of protein. ${ }^{7}$ The current patient similarly had a history of CRF and HD, with the extracted stone found to be composed entirely of protein.

Flank pain is one of the most frequent complaints of patients with matrix stones. ${ }^{1,5}$ As this type of stone is soft in consistency, it can be moulded into the shape of the renal pelvis or the ureter, resulting in complete obstruction. In a series of five patients, Bani-Hani et al. reported that four presented with flank pain and one with acute renal failure. ${ }^{1}$ Similarly, the current case initially presented with left-sided abdominal pain which persisted until the stone was removed.

Non-contrast CT is the gold-standard modality for the diagnosis of urinary stones. ${ }^{9}$ However, as a result of their low mineral content, matrix stones are sometimes not visualised during imaging. This is because most matrix stones are radiolucent on plain X-rays and do not have a typical acoustic shadow on US; moreover, they often appear as filling defects on intravenous and 
retro-grade pyelography., ${ }^{2,9}$ On CT scans, they may look like an egg-shaped mass because the centre of the stone is of soft tissue density with a thin outer rim of calcification. ${ }^{1,9}$

Accordingly, the appearance of a filling defect in a patient with normal renal function and no allergies to contrast agents may indicate the presence of a radiolucent stone. Nevertheless, this diagnosis may be overlooked in those with impaired renal function. As such, a high index of suspicion should be maintained in the presence of any gas in the renal pelvis or unexplained hydronephrosis, particularly among patients with unexplained flank pain. ${ }^{1,2,8}$ In doubtful cases, retrograde pyelography and diagnostic URS should be performed to confirm the diagnosis.

Treatment options for matrix stones are similar to that for calcareous stones, but with some unique differences. As matrix stones are usually large in size, they are very difficult to pass spontaneously; moreover, there is no effective option to dissolve them due to their low mineral content. ${ }^{10}$ Furthermore, as matrix stones are usually radiolucent, accurate localisation for extracorporeal shock wave lithotripsy (ESWL) is problematic. Beltrami et al. reported that ESWL was used as adjuvant therapy in only one case in a series of nine patients; percutaneous nephrolithotomy (PCNL) was the primary method of treatment for six cases, with URS utilised in the remaining three cases. ${ }^{11}$ Among the five cases reported by Bani-Hani et al., one was treated by pyelonephrolithotomy, three by PCNL and one by URS. ${ }^{1}$ Laser therapy may also be utilised in the management of matrix stones. ${ }^{8}$ In the current case, the patient was treated with URS, during which the stone could be removed by forceps extraction alone; however, due to its soft consistency, many attempts were required to ensure complete clearance.

\section{Conclusion}

Although rare, matrix or protein ureteral stones require a high index of suspicion for diagnosis as they are often completely radiolucent and cannot be visualised on CT scans. Female patients and those with UTIs and a history of CRF and HD are at higher risk of matrix stone formation. In most cases, matrix stones can be treated by forceps extraction alone during URS.

\section{References}

1. Bani-Hani AH, Segura JW, Leroy AJ. Urinary matrix calculi: Our experience at a single institution. J Urol 2005; 173:120-3. https://doi.org/10.1097/01.ju.0000145868.18824.25.

2. Rowley MW, Faerber GJ, Wolf JS Jr. The University of Michigan experience with percutaneous nephrostolithotomy for urinary matrix calculi. Urology 2008; 72:61-4. https://doi.org/10.1016/ j.urology.2007.12.080.

3. Canales BK, Anderson L, Higgins L, Frethem C, Ressler A, Kim IW, et al. Proteomic analysis of a matrix stone: A case report. Urol Res 2009; 37:323-9. https://doi.org/10.1007/s00240-009-0213-5.

4. Boyce WH, King JS Jr. Crystal-matrix interrelations in calculi. J Urol 1959; 81:351-65. https://doi.org/10.1016/S0022-5347 (17)66024-5.

5. Shah HN, Kharodawala S, Sodha HS, Khandkar AA, Hegde SS, Bansal MB. The management of renal matrix calculi: A singlecentre experience over 5 years. BJU Int 2009; 103:810-14. https://doi.org/10.1111/j.1464-410X.2008.08065.x.

6. Branten AJ, Assmann KJ, Koene RA. Matrix stones and acquired renal cysts in a non-dialysed patient with chronic renal failure. Nephrol Dial Transplant 1995; 10:123-5. https://doi.org/10.1093/ oxfordjournals.ndt.a090828.

7. Bommer J, Ritz E, Tschöpe W, Waldherr R, Gebhardt M. Urinary matrix calculi consisting of microfibrillar protein in patients on maintenance hemodialysis. Kidney Int 1979; 16:722-8. https://doi.org/10.1038/ki.1979.188

8. Chan $\mathrm{CH}$, El-Hakim A, Andonian S. Renal matrix stone managed by ureteroscopic holmium laser lithotripsy. Can J Urol 2010; $17: 5127-30$

9. Worster A, Preyra I, Weaver B, Haines T. The accuracy of noncontrast helical computed tomography versus intravenous pyelography in the diagnosis of suspected acute urolithiasis: A metaanalysis. Ann Emerg Med 2002; 40:280-6. https://doi.org/10.10 67/mem.2002.126170.

10. Stoller ML, Gupta M, Bolton D, Irby PB 3rd. Clinical correlates of the gross, radiographic, and histologic features of urinary matrix calculi. J Endourol 1994; 8:335-40. https://doi.org/10. 1089/end.1994.8.335.

11. Beltrami P, Ruggera L, Guttilla A, Iannetti A, Zattoni F, Gigli F, et al. The endourological treatment of renal matrix stones. Urol Int 2014; 93:394-8. https://doi.org/10.1159/000357624. 